PREPARED FOR THE U.S. DEPARTMENT OF ENERGY, UNDER CONTRACT DE-AC02-76CH03073

PPPL-3746

PPPL-3746

UC-70

\author{
Plasma Characterization of Hall Thruster \\ with Active and Passive Segmented Electrodes \\ by \\ Y. Raitses, D. Staack, and N.J. Fisch
}

September 2002

NM|

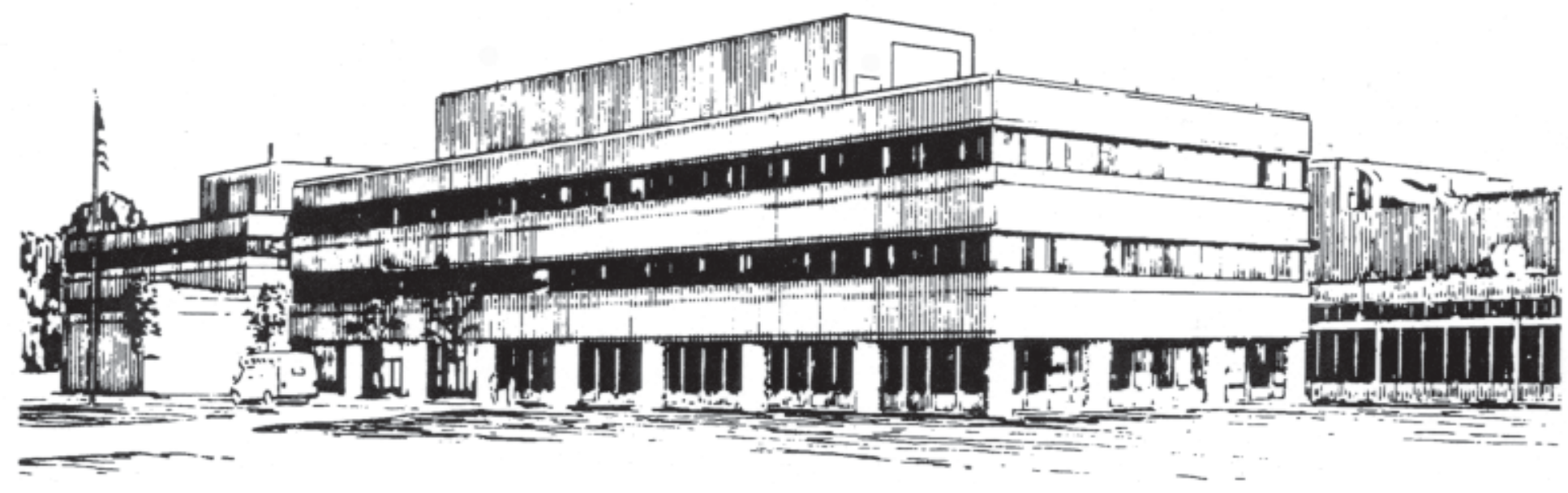

PRINCETON PLASMA PHYSICS LABORATORY PRINCETON UNIVERSITY, PRINCETON, NEW JERSEY 


\section{PPPL Reports Disclaimer}

This report was prepared as an account of work sponsored by an agency of the United States Government. Neither the United States Government nor any agency thereof, nor any of their employees, makes any warranty, express or implied, or assumes any legal liability or responsibility for the accuracy, completeness, or usefulness of any information, apparatus, product, or process disclosed, or represents that its use would not infringe privately owned rights. Reference herein to any specific commercial product, process, or service by trade name, trademark, manufacturer, or otherwise, does not necessarily constitute or imply its endorsement, recommendation, or favoring by the United States Government or any agency thereof. The views and opinions of authors expressed herein do not necessarily state or reflect those of the United States Government or any agency thereof.

\section{Availability}

This report is posted on the U.S. Department of Energy's Princeton Plasma Physics Laboratory Publications and Reports web site in Fiscal Year 2002. The home page for PPPL Reports and Publications is: http://www.pppl.gov/pub_report/

DOE and DOE Contractors can obtain copies of this report from:

U.S. Department of Energy

Office of Scientific and Technical Information

DOE Technical Information Services (DTIS)

P.O. Box 62

Oak Ridge, TN 37831

Telephone: (865) 576-8401

Fax: (865) 576-5728

Email: reports@adonis.osti.gov

This report is available to the general public from:

National Technical Information Service

U.S. Department of Commerce

5285 Port Royal Road

Springfield, VA 22161

Telephone: $1-800-553-6847$ or

(703) $605-6000$

Fax: (703) 321-8547

Internet: http://www.ntis.gov/ordering.htm 


\title{
Plasma Characterization of Hall Thruster with Active and Passive Segmented Electrodes
}

\author{
Y. Raitses, D. Staack and N. J. Fisch \\ Princeton Plasma Physics Laboratory, Princeton, NJ 08540
}

\begin{abstract}
Non-emissive electrodes and ceramic spacers placed along the Hall thruster channel are shown to affect the plasma potential distribution and the thruster operation. These effects are associated with physical properties of the electrode material and depend on the electrode configuration, geometry and the magnetic field distribution. An emissive segmented electrode was able to maintain thruster operation by supplying an additional electron flux to sustain the plasma discharge between the anode and cathode neutralizer. These results indicate the possibility of new configurations for segmented electrode Hall thruster.
\end{abstract}

\section{Introduction}

A Hall thruster with segmented electrodes along the thruster channel can have certain advantages over conventional non-segmented thruster configurations, particularly with regard to plume divergence, thruster lifetime and thruster compatibility with a satellite. In the case of metal electrodes, which can be emissive or non-emissive, the electrodes provide additional control of the plasma flow in the thruster channel $[1,2]$. Active control of the plasma, or multi stage operation may be implemented by biasing these electrodes with different voltages from the main discharge or separate power supplies $[3,4]$.

The effect of non-emissive electrodes on the plasma potential distribution and plume angle was already measured and to some extent explained by the lower secondary electron emission of metal electrodes compared to that of ceramic channel walls [3-5]. Because of the plasma-electrode sheath, these effects were weakly sensitive to changes in the potential of the negative side electrode from floating to cathode biased [1,3]. By applying the bias

Copyrights @ 2002 by the American Institute of Aeronautics and Astronautics Inc. All rights reserved voltage to the positive side electrode, the possibility of a two-stage operation was demonstrated [4].

As a variation on the theme of passive, i.e., not biased, segmented electrodes, they can be made from ceramics with different secondary electric emission coefficients, larger or smaller than the channel wall material. A combination of such "electrodes" along the channel may allow, for example, a favorable distribution of the electron temperature to reduce energy spread of the exhausted ions.

Direct control of the electric field along the channel can be accomplished with emissive electrodes [1,2]. By emitting electrons from a metal surface, the plasma-electrode sheath can be almost eliminated and therefore, the magnetic field lines forms precise equipotential surfaces. Hence, biased segmented electrodes should be able to establish a very abrupt potential drop in the plasma along the channel [2].

This highly simplified picture of plasma dynamics of segmented electrode Hall thruster requires further theoretical and experimental studies. We present here new results for segmented thruster configurations with ceramic spacers and with an emissive electrode. We compare also these results with those measured for non-segmented and non-emissive segmented electrode configurations.

\section{Experimental Setup and Procedure}

The $9 \mathrm{~cm}$ diameter laboratory Hall thruster (Fig. 1), test facility and diagnostics used in this study have been described in detail in Refs. 2-5. The thruster channel is made from boron nitride ceramic and has an inner wall $4 \mathrm{~mm}$ shorter than the outer wall in order to incorporate inner segmented electrodes or ceramic spacers of the same $4 \mathrm{~mm}$ length. For non-segmented thruster configuration, referred to as WS, a spacer made from the same boron nitride ceramic as the channel material extends the inner wall up to the exit plane. In addition to a floating graphite 
electrode (Fig. 1), the passive electrode configurations were implemented with two ceramic spacers made from a quartz and $\mathrm{MACOR}^{\mathrm{TM}}$ (machinable glass ceramic). In the text below we shall refer to these segmented configurations as GS, MS and QS, respectively. Fig. 2 shows secondary electron emission properties of relevant materials [6-9]. Though there is no published data on secondary electron emission for MACOR glass ceramic, which consists mainly from mica and $\mathrm{SiO}_{2}$, Ref. 10 reported on differences in the thruster operation, which tend to increase with the discharge voltage. This behavior might be associated with differences in the secondary electron emission for boron nitride and MACOR ceramics used in this study for the channel. The placement of the graphite electrode and ceramic spacers relative to the magnetic field distribution is shown in Fig. 3.

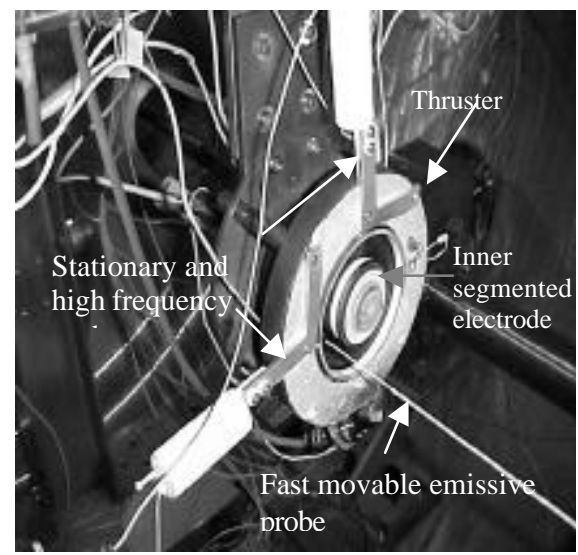

Fig. 1 Segmented electrode Hall thruster and probe setup.

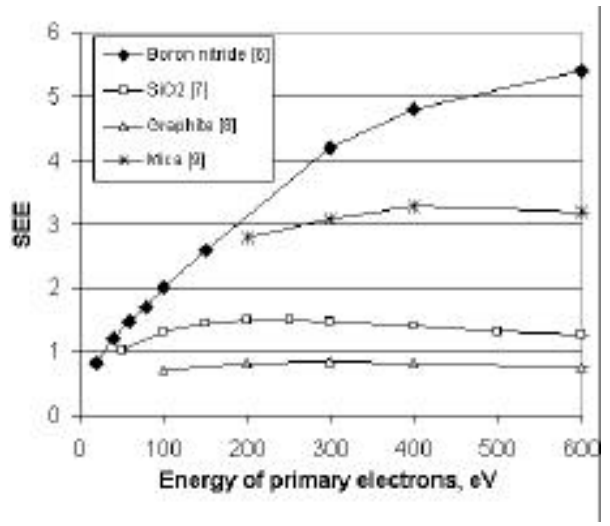

Fig. 2 Secondary electron emission data from refs 6-9 for materials relevant to this study.

Fig. 4 shows the emissive electrode, which consists of a dispenser tungsten ring with a heater-filament incorporated inside the ring. The space between the filament and the ring is filled with a sintered alumina ceramic material to electrically insulate the filament body and provide a heat flux to the ring by a thermal conductivity. The filaments ends, one of which was welded to the ring, were connected electrically to a separate external circuit of a ground insulated heating power supply. The circuit was used to switch between the cathode biased and floating operating modes of the electrode. In order to incorporate the electrode on the inner wall and wire its filament, the inner magnetic pole and the electrode were shifted forward. As a result, the electrode protrudes 1.5 $\mathrm{mm}$ beyond the outer wall. Fig. $3 \mathrm{c}$ shows the magnetic field profile along the channel median.

(a)

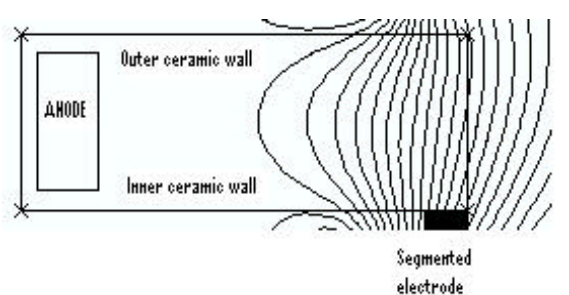

(b)

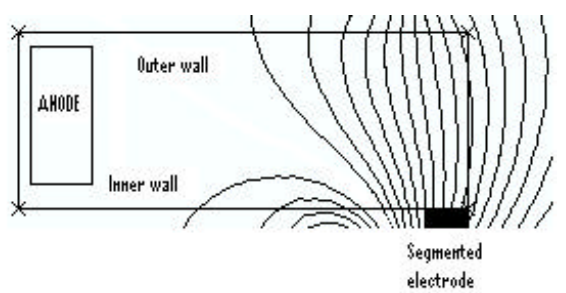

(c)

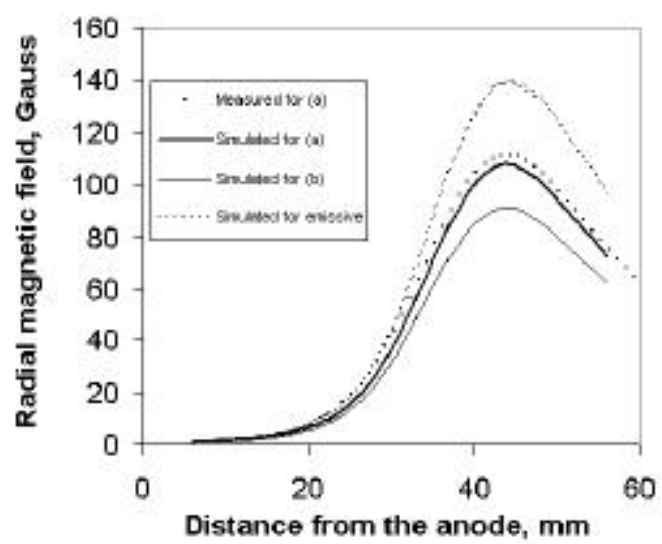

Fig. 3 Non-linear simulations and measurements of the magnetic field distribution for different coils current ratios (a) and (b) and the radial component of the applied magnetic field along the channel median (c). The thruster exit is at 46 mm. 
The measurements of the plasma potential in non-emissive segmented and non-segmented thruster configurations were performed at the same operating conditions, namely, discharge voltage of $250 \mathrm{~V}$ and xenon gas flow rate of 1.7 $\mathrm{mg} / \mathrm{s}$, and for two types of the magnetic field distribution (Fig. $3 \mathrm{a}$ and b).

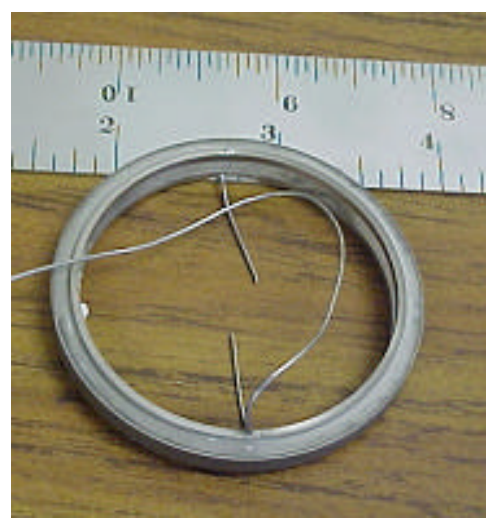

Fig. 4 Emissive segmented electrode constructed from a dispenser tungsten ring with a heater filament incorporated inside the ring and insulated by a sintered ceramic material.

The procedure of the floating emissive probe measurements was described in detail in Ref. 11. In each thruster configuration, potential profiles were measured for several radial positions of the probe. Reproducibility of probe measurements was not less than $85 \%$. The major source of irreproducibility was probe-induced perturbations of the thruster discharge (Fig. 5). Detail analysis of these perturbations is given in Ref. 12.

As for the emissive electrode configuration, the main purpose of this preliminary set of experiments was an integration test of Hall thruster operation with this segmented electrode. The thruster was operated at discharge voltages from $170 \mathrm{~V}$ to $270 \mathrm{~V}$ and Xenon gas mass flow rate of $1.7 \mathrm{mg} / \mathrm{s}$. Measurements were limited by electrical characteristics of the discharge and electrode. In addition, the electrode temperature was measured with an optical pyrometer, which was calibrated by a thermocouple in a separate experimental setup without thruster operation.

\section{$\underline{\text { Results and Discussions }}$}

\section{Non-emissive electrode and ceramic spacers}

In all thruster configurations, the thruster operation was accompanied by low frequency discharge oscillations (Figs. 5 and 6), which are a type of ionization instability suggested in Ref.
13. The amplitude of these oscillations and the discharge current were strong, in particular for the thruster with a quartz spacer when the magnetic field distribution of Fig. 3a was applied. As a result, probe measurements were difficult to implement for this thruster configuration. When the magnetic field was changed to the distribution of Fig. 3b, the discharge current in the QS configuration decreased by almost twice and became comparable to the other thruster configurations, operated, however, with larger amplitude of low frequency oscillations except the MS case (Fig. 6). In general, this unstable operation of the thruster introduces additional uncertainties in the probe measurements.
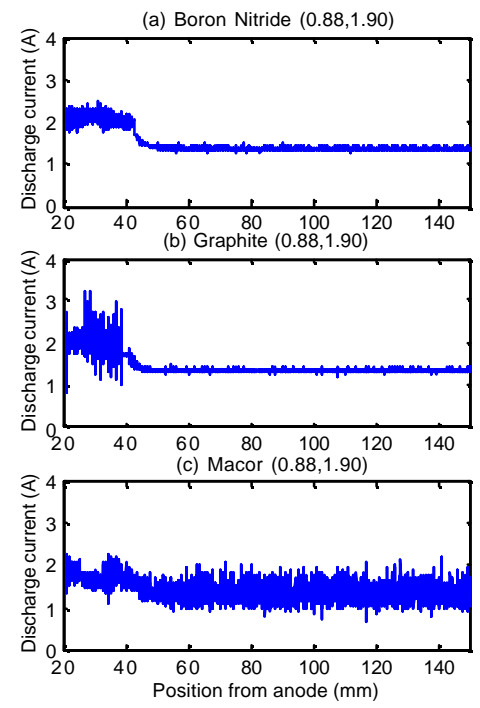

Fig. 5 Discharge current traces before and during the probe immersion for WS (a), GS (b) and MS (c) configurations. The thruster was operated with the magnetic field distribution of Fig. $3 b$. The channel exit is $46 \mathrm{~mm}$ from the anode.

Fig. 7 shows the results of the plasma potential measurements for the magnetic field distribution of Fig. 3a. For the WS and MS thruster configurations the defocusing shape of equipotentials is caused by the electron pressure gradients towards the walls [1]. A hydrodynamic model of Ref. 5 showed that the unusual concave shape of equipotentials obtained for the GS thruster configuration can be attributed to a nonuniform distribution of the electron pressure in the GS thruster channel with a different secondary electron emission of the inner and outer walls at the same energy of the primary electrons from the plasma. 

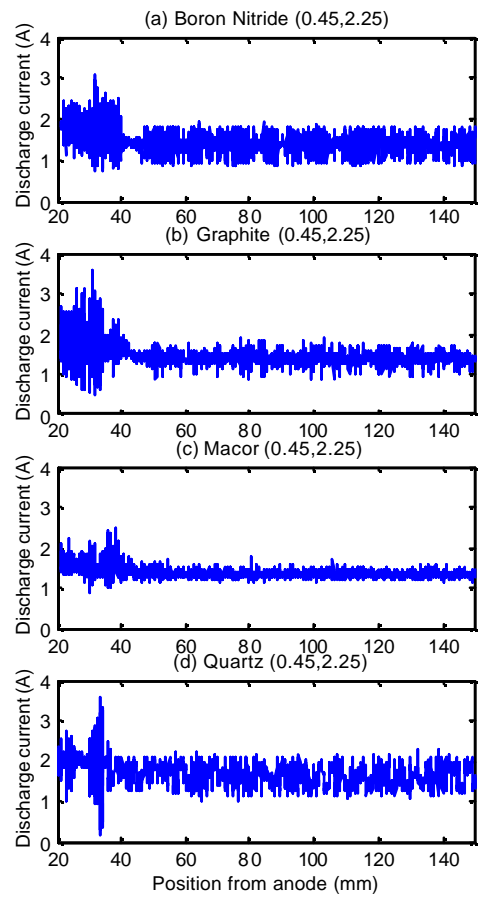

Fig. 6 Discharge current traces before and during the probe immersion for WS (a), GS (b) and MS (c) and QS (d) configurations. The thruster was operated with the magnetic field distribution of Fig. 3b. The channel exit is $46 \mathrm{~mm}$ from the anode.

Interestingly, other researchers obtained a similar shape of equipotentials for a conventional Hall thruster operated at large mass flow rates [14]. In these particular regimes, larger plasma density and electron temperature were measured near the outer channel wall. For the GS configuration, the model of Ref. 5 predicts a higher electron temperature near the inner wall with a lower secondary electron emission.

The inner shift of the acceleration region for the GS relative to the non-segmented configuration is also consistent with a lower secondary electron emission of the electrode $[5,15]$. Following the same hydrodynamic model, results for the MS and WS configurations suggests that a MACOR material has secondary electron emission similar or even larger than boron.*

\footnotetext{
* While preparing this paper we got first results for SEE of MACOR, BN and Quartz materials using a recently developed SEE measurement setup at the PPPL indicating that boron nitride has lower secondary electron emission than MACOR and Quartz at energy of primary electrons $\leq 30-40 \mathrm{eV}$ [16].
}
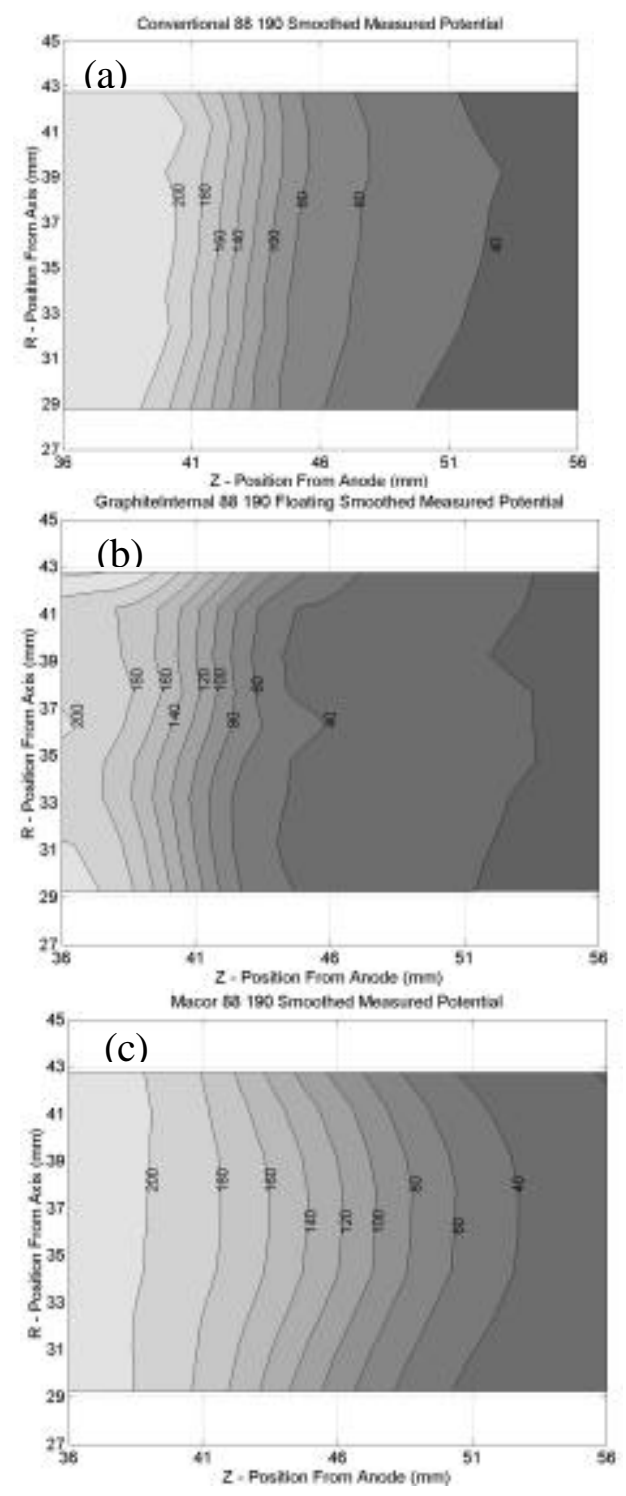

Fig. 7 Plasma potential distribution measured for non-segmented (a), graphite segmented (b) and glass ceramic spacer (c) thruster configurations operated with the magnetic field distribution shown in Fig. 3a. The channel exit is $46 \mathrm{~mm}$ from the anode.

In comparison to previous studies of the effect of the channel wall material $[10,15,17-$ 19] some of the measured results for the segmented thruster appear different. Ref. 17 predicted an outward shift of the acceleration region for materials with lower secondary electron emission. According to Ref. 10 an exchange of the entire channel material from MACOR to boron nitride created almost the same changes in operation of the thruster (increase of $\mathrm{I}_{\mathrm{d}}$ for MACOR channel $\sim 0.05 \mathrm{~A}$ at 
$250 \mathrm{~V}$ and $1.7 \mathrm{mg} / \mathrm{s}$ ) as those reported here for the thruster with a short glass ceramic spacer (for $\mathrm{BN} I_{d}=1.57 \mathrm{~A}$ and for $I_{d}=1.64 \mathrm{~A}$ at $250 \mathrm{~V}$ and $1.7 \mathrm{mg} / \mathrm{s}$ ). Since the thruster of Ref. 10 had a smaller channel it is not clear if this simila rity in changes of the discharge current for the segmented electrode, which is placed on the inner wall, suggests that the interaction of plasma with this wall contributes more significant to the electron transport in Hall thrusters than that with the outer wall. It seems, however, that the effect of the channel material depends on sizes of the segmented electrodes and their precise placement in the channel.

Note that in Ref. 18, larger discharge current for a channel made from alumina ceramic rather than from $\mathrm{BN}$ was attributed to the higher secondary electron emission of the alumina. Though we observed similar results for the WS and MS configurations, the discharge current for graphite electrode was larger $(1.61 \mathrm{~A})$ than that for the WS configuration. Furthermore, as shown below, under different operating conditions, the dependence of the discharge current on the physical properties of the channel wall material varies significantly.

Besides the physical properties of the channel material and the segmented electrode geometry, the magnetic field can strongly influence the location of the acceleration region and shape of equipotentials. When the magnetic field distribution of Fig. 3b was applied for the non-segmented thruster, the acceleration region moved towards the anode (Fig. 8) as compared to its original placement (Fig 7). Though this result is not understood, it could be related to oscillating operation of the thruster with bursts combined with large probe-induced perturbations in this particular regime (Fig. 6). Moreover, the change of the shape of magnetic field lines changed the shape of equipotentials from concave to defocusing in the GS case and increased the curvature of defocusing equipotentials for the MS configuration. These results are consistent with larger plume angles measured for these thruster configurations.

Since quartz has a higher secondary electron emission than the graphite, we might expect that the location of the acceleration region in the QS thruster configuration should be downstream of that for the GS thruster case. As seen in Fig. 7, this is opposite to the measured results. Perhaps, this inconsistency is also caused by the large amplitude discharge oscillations measured for this configuration (Fig. 6).
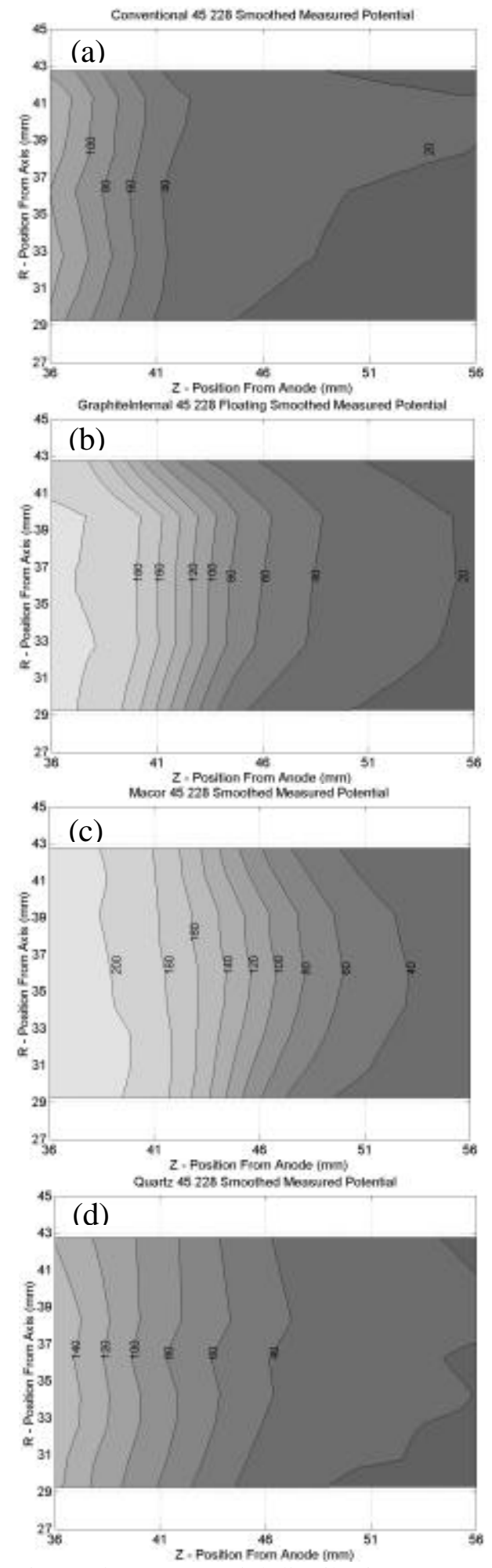

Fig. 8 Plasma potential distribution measured for non-segmented (a), graphite segmented (b) glass ceramic (c) and quartz (c) spacers thruster configurations operated with the magnetic field distribution shown in Fig. 3b. The channel exit is $46 \mathrm{~mm}$ from the anode. 
Interestingly, in comparison to the results measured for the magnetic field distribution of Fig. 3a, a different dependence of the discharge current on segmented electrode configuration was obtained for the magnetic field distribution of Fig. 3b. For the larger secondary electron emission MACOR spacer the discharge current was smaller $(1.63 \mathrm{~A})$ than that for the graphite electrode (1.66A) and boron nitride channel (1.7A). For the QS configuration, the discharge current was 1.94 A mainly because of a larger axial electron current as compared to the other segmented configuration. A possible explanation of these different results is as follows. For each thruster configuration there is an optimal magnetic field at which the discharge current reaches its minimum $[1,20]$. Above or below this minimum, large amplitude low frequency discharge oscillations contribute to the axial electron current across the magnetic field [13]. The segmented electrodes made from different materials can also affect this electron transport in different ways depending on physical properties of these materials. Therefore, it is reasonable to expect that for different segmented thruster configuration operated under the same mass flow rates and discharge voltages there are different optimal magnetic field distributions. Indeed, as seen in Figs. 5 and 6, for the magnetic field distribution of Fig. 3a, the amplitude of discharge current oscillations are smaller for the $\mathrm{BN}$ and GS cases than for the MS, but for the magnetic field distribution of Fig. 3b, the amplitude of these oscillations and the discharge current were smaller in the MS case.

In addition to changes of the location of the acceleration region and discharge current, a lower secondary electron emission should lead to fewer electron collisions with the channel walls and, as a result, to a shorter acceleration region, $L_{a c l} \propto \sqrt{v_{e} / v_{i o n}}$, where $v_{e}$ and $v_{i o n}$ are the total electron and ionization collision frequencies, respectively [20]. Moreover, the electrons should gain higher temperatures increasing the frequency of ionizing collisions and, as a result, the discharge current $[15,21]$. In general, all these predictions are consistent with the measured results for the segmented electrodes and ceramic spacers. As seen in Figs 7 and 8 , the voltage potential drop takes place over shorter region for the GS and WS thruster cases than for the MS and QS configurations.

In comparison to the effect of ceramic spacers, conductive properties of the graphite electrode can also affect the plasma-wall interaction in the segmented Hall thruster. Basically, since the metal surface of the electrode is an equipotential it collects locally unequal electron and ion fluxes from the plasma, $J_{e r}(z) \neq J_{i z}(z)$ while still maintaining zero total net current, $\Sigma I_{r}=0$. An illustrative example of electron and ion fluxes collected by the floating graphite electrode is shown in Fig. 9. These estimated results were partially derived from plasma potential, $\Phi_{p l}(z)$ and floating potential $\Phi_{f l}(z)$ profiles and the total ion flux, $J_{i T}$, measured for the GS thruster configuration. For simplicity of these qualitative estimations, the plasma density along the channel was determined as $n_{0}(z)=J_{i T} / e V_{i o n}(z) . V_{\text {ion }}(z)=\sqrt{2 e \Delta F_{p l}(z) / M_{\text {ion }}}$ is the ion velocity and $M_{i o n}$ is the atom mass. The other assumptions include: Boltzmann's distribution for the electron density along the magnetic field lines and the Bohm velocity for the ions at the sheath edge [15], $V_{i B}=\left[k T_{e}(z) / M_{i o n}\right]^{0.5}$, where $T_{e} \approx 1 / 2\left(\Phi_{p l}-\Phi_{f l}\right) / \operatorname{Ln}\left(M_{i o n} / 2 \pi m_{e}\right)$ is the electron temperature derived from cold and hot probe measurements neglecting uncertainties affected by a flowing plasma and double sheath at the hot probe [22]. Then, $J_{i r}(z)=1 / 2 e n_{0}(z) V_{i B}(z)$, and $J_{e r}(z)=1 / 4 e n_{0} \exp \left[-e \Delta \Phi_{W} / k T_{e}(z)\right] V_{e t h}$, where $V_{\text {eth }}$ is the electron thermal velocity. Hence, neglecting electrical resistance of the electrode, its floating potential relative to the plasma, $\Delta \Phi_{W}$, was used as a fitting parameter to fulfill the condition of $\Sigma I_{r}=0$. The measured and estimated floating potentials relative to the ground are $12.5 \mathrm{~V}$ and $18 \mathrm{~V}$, respectively. The reduction of the electron flux along the electrode (Fig. 9) means fewer electron-wall collisions [17]. Thus, in addition to a lower secondary electron emission of a graphite electrode, its conductive properties can contribute to a contraction of the acceleration region measured for the GS thruster case as compared to the other configurations with dielectric walls.

\section{Emissive electrode}

Electrons emitted from the floating surface partially neutralize the positive ion space charge near the surface, reducing the sheath voltage drop and increasing the electron flux from the plasma. In this case, the floating potential of the emitting surface is determined by the zero net current condition, which, in addition to the collected electron and ion fluxes, includes the term of the emitted electron flux [23]. For the segmented electrode thruster, the reduction of the sheath potential drop means an increase of the floating potential of the electrode relative to the 
cathode. Indeed, for the emissive electrode, thruster operated at $250 \mathrm{~V}$, the floating potential of the electrode relative to the cathode increased from $21 \mathrm{~V}$ to $30 \mathrm{~V}$ and then almost saturated with the heating power of the electrode filament. At the input power of $200 \mathrm{~W}$, a dispenser tungsten ring of the electrode reached $1000 \mathrm{C}$. That should be hot enough for operation of the electrode with a strong emission. However, since the temperature of plasma electrons collected by the electrode is much higher than that of emitted electrons, the electron emission current is space charge limited by a double layer, which is formed near the electrode surface [22, 23]. This may be the reason for the observed saturation of the floating potential with the heating power and for almost no change of the discharge current with the heating power (Fig. 10).

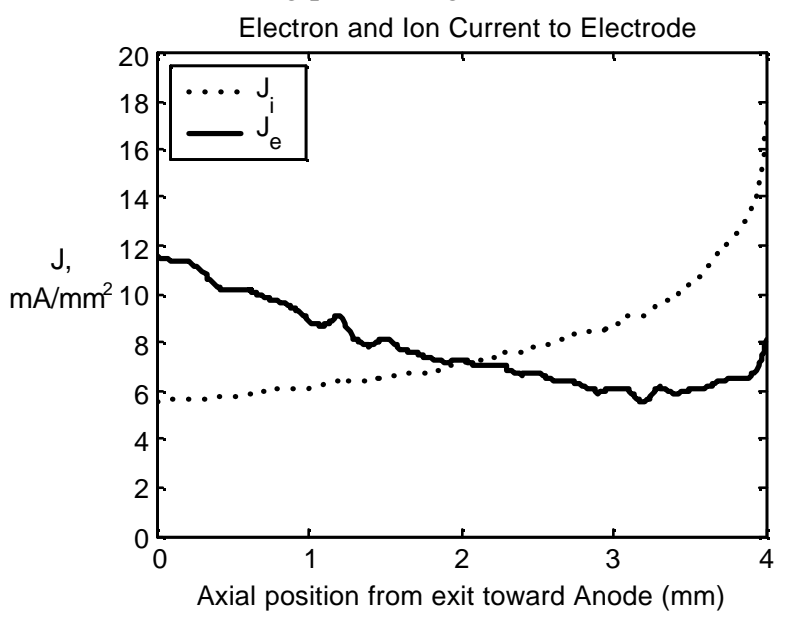

Fig. 9 Estimated ion and electron radial fluxes from the plasma to the floating non-emissive segmented electrode (4 mm length).

When the cathode bias voltage was applied to the cold electrode, the current measured in the electrode circuit was $0.110 \mathrm{~A}$, i.e., the electrode acts as an ion collector [3]. An increase of the heating power causes an increase of the emission current and, as a result, the total current through the electrode (Fig. 10). At a heating power of $340 \mathrm{~W}$, the electrode current measured in the electrode circuit was 0.267 A. Subtracting the ion collection current measured for the cold electrode, the electron emission current is 0.157 A. As seen in Fig. 10, the current measured in the anode circuit of the main discharge power supply is almost not changed or increases insignificantly with the heating power up to $300 \mathrm{~W}, 346 \mathrm{~W}$, respectively. The meaning of these results is that the cathode biased emissive electrode is able to supply an electron flux in order to provide a quasineutrality of the plasma in the channel with and, possibly, without an electron flux from the cathode-neutralizer.

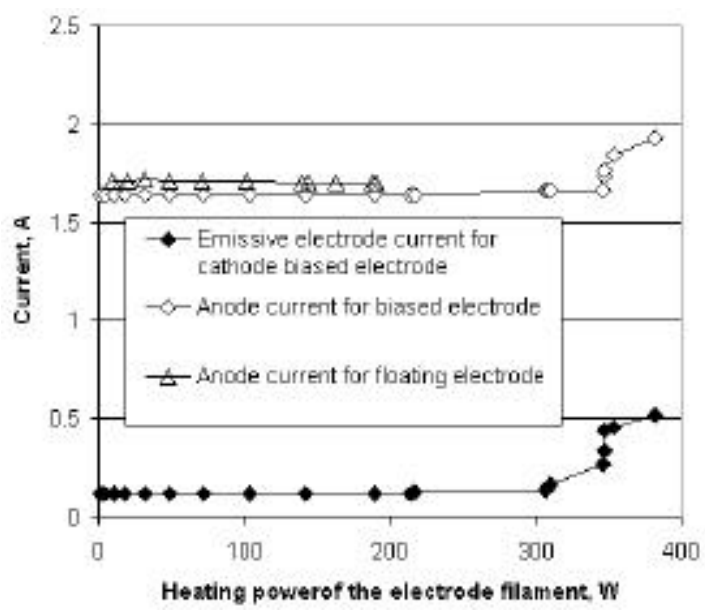

Fig. 10 Anode current for floating and cathode biased emissive segmented electrode cases and segmented electrode current for the biased electrode configuration as a function of the heating power applied to the electrode filament. The thruster operated at $250 \mathrm{~V}$ and $1.7 \mathrm{mg} / \mathrm{s}$ with the magnetic field distribution of Fig. 3c.

After operation of the thruster with the electrode heated to $346 \mathrm{~W}$ for more than 20 minutes, both the anode and electrode currents increased drastically in a short period of time. Post-run inspection of the thruster channel revealed that the whole ceramic channel walls were coated with a thin metal coating, which could result from sputtering and evaporation of the electrode.

\section{Conclusions}

We showed that segmented electrodes, made from metal or ceramic spacers and having sizes comparable, but smaller than the acceleration region, can significantly affect the plasma potential distribution and shape of equipotentials in the Hall thrusters. Mechanisms behind these effects involve changes in the electron temperature and electron transport by physical properties of the electrodes, such as secondary electron emission and conductivity. In addition to the physical properties and operating conditions of the thruster, the effect of the channel material depends on geometry and precise placement of the electrodes relative to the magnetic field distribution. These results are partially consistent with a hydrodynamic model. 
In general, it may be possible to apply a combination of ceramic and metal electrodes with different secondary electron emission and conductive properties along the channel and on opposite channel walls in order to achieve more versatility in control of the plasma flow in Hall thrusters. Such control can be useful for, for example, a better separation of the ionization and acceleration regions. This separation may improve the energy spectrum of the exhausted ion beam. For this purpose, precise knowledge of secondary electron emission for electrode materials in the relevant energy range of primary electrons from the plasma is crucial. Therefore, we have recently developed, built and operated an experimental setup for secondary electron emission measurements from dielectric and conductive materials in the energy range of primary electrons from a few eV to $\mathrm{keV}$ [16].

In experiments with an emissive segmented electrode, we showed that, when this electrode is biased, it can supply electrons to sustain the discharge possibly even without an electron flux from the cathode neutralizer to the anode. However, we encountered difficulties associated with metal coating of ceramic channel walls, caused by sputtering and evaporation of the hot emissive electrode. As a result, the thruster switched to a large discharge current operating mode at the same discharge voltage. To reduce this coating effect, grooved channel walls, suggested in Ref. [3], may be useful.

Note, since the emissive electrode supplies relatively cold electrons to the plasma, it may also control, for example, the electron temperature and plasma density in the Hall thruster channel with metal walls. In this case, the coating from a hot electrode may be not a problem.

\section{Acknowledgement}

The authors wish to thank Dr. M. Keidar, Dr. A. Dunaevsky and Mr. L. A. Dorf for fruitful discussions.

This work was supported by grants from the New Jersey State Commission on Science and Technology and by the US DOE under Contract No. DE-AC02-76CHO3073.

\section{$\underline{\text { References }}$}

1. A. I. Morozov and V. V. Savelyev, in Review of Plasma Physics, edited by B.B. Kadomtsev and V. D. Shafranov, Consultants Bureau, New York, 2000, Vol. 21, p. 223.
2. N. J. Fisch, Y. Raitses, L. A. Dorf and A. A. Litvak, AIAA paper 99-2572, Los Angeles, CA, June 1999.

3. Y. Raitses, L. A. Dorf, A. A. Litvak and N. J. Fisch, J. Appl. Phys. 88, 1263, 2000.

4. N. J. Fisch, Y. Raitses, L. A. Dorf and A. A. Litvak, J. Appl. Phys. 89, 2040, 2001.

5. Y. Raitses, M. Keidar, D. Staack and N. J. Fisch, Submitted to Journal of Appl. Phys.

6. J. B. Bugeat and C. Koppel, IEPC paper-9535, the $24^{\text {th }}$ IEPC conference, Moscow, 1995.

7. G. F. Dionne, J. Appl. Phys. 46, 3347, 1975.

8. Bronstein I.M. and Frainman B.S., in "Vtorichnaya Elektronnaya Emissiya", Nauka, Moscow, p.340, 1969.

9. L.N Dobretsov and T.L Matskevich, Sov. Phys.-Tech. Phys. 2, 663, 1957.

10. Y. Raitses, J. Ashkenazy and G. Appelbaum, IEPC paper 97-056, the $25^{\text {th }}$ Inter. Electric Propulsion Conf., Cleveland, OH, 1997.

11. Y. Raitses, D. Staack and N. J. Fisch, IEPC01-060, the $27^{\text {th }}$ Inter. Electric Propulsion Conf, Pasadena, CA 2001.

12. D. Staack, Y. Raitses and N. J. Fisch, AIAA paper 2002-4109, Indianapolis, IN, July 2002.

13. J.P. Boeuf and L. Garrigues, J. Appl. Phys. 84, 3541 (1998).

14. J. M. Haas and A. D. Gallimore, AIAA paper-00-3422, Huntsville, Al, July 2000.

15. M. Keidar, I. D. Boyd and I. I. Beilis, Physics of Plasmas, 8, 5315, 2001.

16. A. Dunaevsky, Y. Raitses and N. J. Fisch (in preparation).

17. V. V. Egorov, V. Kim, A. A. Semenov and I. I. Shkarban, in Ion Injectors and Plasma Accelerators, edited by A. I. Morozov and N. N. Semashko. Energoizdat, Moscow, 1990, p. 56. [in Russian]

18. N. Gascon, N. B. Mezan and M. A. Cappelli, IEPC-01-56, the $27^{\text {th }}$ Inter. Electric Propulsion Conf., Pasadena, CA, 2001.

19. S. Locke, U. Shumlak and J. M. Fife, IEPCpaper-01-23, the $27^{\text {th }}$ Inter. Electric Propulsion Conf., Pasadena, CA, 2001.

20. V. Kim, Journal of Propulsion and Power, 14, 736, 1998.

21. E. Y. Choueiri, Physics of Plasmas, 8, 5025, 2001.

22. N. Hershkowitz, in Plasma Diagnostics, Discharge Parameters and Chemistry, edited by O. Auicello and D. Flam, Academic Press, p. 1491989.

23. V.A.Rozhansky, and L.D.Tsendin, Transport Phenomena in Partially Ionized Plasma, Taylor \& Francis Group, London, 2002. 


\section{External Distribution}

Plasma Research Laboratory, Australian National University, Australia

Professor I.R. Jones, Flinders University, Australia

Professor João Canalle, Instituto de Fisica DEQ/IF - UERJ, Brazil

Mr. Gerson O. Ludwig, Instituto Nacional de Pesquisas, Brazil

Dr. P.H. Sakanaka, Instituto Fisica, Brazil

The Librarian, Culham Laboratory, England

Mrs. S.A. Hutchinson, JET Library, England

Professor M.N. Bussac, Ecole Polytechnique, France

Librarian, Max-Planck-Institut für Plasmaphysik, Germany

Jolan Moldvai, Reports Library, MTA KFKI-ATKI, Hungary

Dr. P. Kaw, Institute for Plasma Research, India

Ms. P.J. Pathak, Librarian, Insitute for Plasma Research, India

Ms. Clelia De Palo, Associazione EURATOM-ENEA, Italy

Dr. G. Grosso, Instituto di Fisica del Plasma, Italy

Librarian, Naka Fusion Research Establishment, JAERI, Japan

Library, Plasma Physics Laboratory, Kyoto University, Japan

Research Information Center, National Institute for Fusion Science, Japan

Dr. O. Mitarai, Kyushu Tokai University, Japan

Library, Academia Sinica, Institute of Plasma Physics, People's Republic of China

Shih-Tung Tsai, Institute of Physics, Chinese Academy of Sciences, People's Republic of China

Dr. S. Mirnov, TRINITI, Troitsk, Russian Federation, Russia

Dr. V.S. Strelkov, Kurchatov Institute, Russian Federation, Russia

Professor Peter Lukac, Katedra Fyziky Plazmy MFF UK, Mlynska dolina F-2, Komenskeho Univerzita, SK-842 15 Bratislava, Slovakia

Dr. G.S. Lee, Korea Basic Science Institute, South Korea

Institute for Plasma Research, University of Maryland, USA

Librarian, Fusion Energy Division, Oak Ridge National Laboratory, USA

Librarian, Institute of Fusion Studies, University of Texas, USA

Librarian, Magnetic Fusion Program, Lawrence Livermore National Laboratory, USA

Library, General Atomics, USA

Plasma Physics Group, Fusion Energy Research Program, University of California at San Diego, USA

Plasma Physics Library, Columbia University, USA

Alkesh Punjabi, Center for Fusion Research and Training, Hampton University, USA

Dr. W.M. Stacey, Fusion Research Center, Georgia Institute of Technology, USA

Dr. John Willis, U.S. Department of Energy, Office of Fusion Energy Sciences, USA

Mr. Paul H. Wright, Indianapolis, Indiana, USA 
The Princeton Plasma Physics Laboratory is operated by Princeton University under contract with the U.S. Department of Energy.

\author{
Information Services \\ Princeton Plasma Physics Laboratory \\ P.O. Box 451 \\ Princeton, NJ 08543
}

Phone: 609-243-2750

Fax: 609-243-2751

e-mail: pppl_info@pppl.gov

Internet Address: http://www.pppl.gov 